\title{
Environmental Crisis and Environmental Policies in Asian Countries
}

\author{
Peter Pintz*
}

\section{INTRODUCTION}

After the 1972 UN conference on "The Human Environment" an increasing number of countries in the developing world initiated environmental policies. This process, however, gained momentum only slowly, as the view was still widely prevailing (and particularly supported by India and Brazil) that environmental protection was a privilege of the industrial countries which developing countries cannot afford. The 1972 conference also brought about a change in the concept of human environment which adapted to the actual conditions and priorities in developing countries by widening the definition and encompassing deforestation, desertification, inadequate water supply, lack of sanitation, poor housing facilities, etc. It was also made clear that in addition to "industrialization-induced" environmental pollution, developing countries suffer particularly from "poverty-induced" environmental hazards.

This paper reviews the development of environmental management in Asian developing countries during the Seventies and Eighties and analyses shortcomings of environmental policies in these countries. It also gives an overview of environmental pollution and damages in order to judge the success or failure of environmental policies, and analyses some of the main causative factors of environmental pollution. The paper cannot deal with national characteristics, but has to confine itself to features which are more or less common to most countries and thus focuses on general trends and developments.

\section{ENVIRONMENTAL LEGISLATION THE BASIS FOR ENVIRONMENTAL POLICY}

Environmental legislation has to be seen as an essential prerequisite for environmental policy by which objectives, areas of an adopted policy and prevailing values are transformed into codes of conduct. The environmental laws enacted in many Asian countries before the Seventies were mainly confined to a very narrow area in the sense of natural habitat and wildlife conservation. Many of them did not also

*The author is representative of the Friedrich-Ebert-Stiftung (West Germany) at the Pakistan Institute of Development Economics. 
have the intention to protect natural resources, but rather to regulate their utilization. They cannot thus, be regarded as an adequate basis of environmental management as they lack the kind of control mechanism which is essential to any genuine environmental policy.

Only in very few Asian countries, e.g. Singapore and to some extent the Philippines, prior to the 1972 legislation had been enforced which had a comprehensive approach to environmental protection or at least covered important sectoral environmental problems, such as water pollution, air pollution, disposal of hazardous waste, etc. Immediately after the 1972 Stockholm Conference environmental legislation started being enacted in Asian countries, as the importance of legislation as a tool for environmental management acknowledged more and more. This develop. ment culminated in the second half of the Seventies, when most of the countries still without legislation introduced new environmental laws and others amended existing laws to improve them and adjust them to the new environmental hazards or enforced laws for areas so far not covered. In the 1980s some latecomers completed the picture of environmental legislation. Pakistan, e.g. promulgated the Environmental Protection Ordinance only in December 1983.

Nowadays almost all Asian countries have substantial environment-oriented laws. The status of the legislation however varies considerably from country to country. Regarding its range, the legislation can loosely be classified in three categories (ESCAP 1984): (a) umbrella type of environmental legislation (China, Pakistan, the Philippines, South Korea); (b) umbrella type supplemented by legislation in sectoral areas (Indonesia, Malaysia, Sri Lanka, Thailand); (c) sectoral legislation dealing with specific environmental problems (Bangladesh, Hong Kong, India, Iran, Papua New Guinea, Singapore).

It is also notable that in quite a number of Asian countries the constitution specifically refers to the protection of the environment and natural resources (e.g. in China, India, Indonesia, Pakistan, Papua New Guinea, South Korea, Sri lanka, the Philippines) (ESCAP 1984; Shane 1979). However, provisions in the constitution are not a necessary prerequisite for serious environmental policy, as experiences from some countries show. The existence of such constitutional provisions, on the other hand, does not necessarily mean that a sincere and efficient environmental policy is actually practised.

The environmental legislation in Asian developing countries has been enhanced and improved considerably in the Seventies and early Eighties and can constitute an important basis for environmental protection, if implemented vigorously. Without doubt, however, there is a need to further strengthen legal provisions, as their efficiency is hampered by quite a number of deficiencies. So far in many countries environmental legislation neglects various aspects of pollution and does not cover other aspects adequately. Especially the fields of hazardous substances, solid wastes recycling and re-use of wastes, coastal environments, mining and pesticide control have to be covered additionally and/or legislation in these areas has to be strengthened [(ESCAP (1984); Bull (1983)]. In many cases the gestation period of environmental laws is too long so that they can be used only after serious environmental damages have occurred already and not for preventive strategies.

An observation made in India by the Centre for Science and Environment (1982) that many environmental laws put more emphasis on promotion of resource utilization for economic benefits than on careful analysis of deleterious effects on the environment, holds true for other countries as well. This can partly be explained by the fact that new laws are sometimes only updated versions of earlier ones and therefore, do not reflect new developments.

Furthermore, legislation frequently includes only vague aims and does not clearly state its objectives. This means that substantial discretion is given to the administrators whose interpretation is often not in conformity with the intended purpose of the law (e.g. when standards have to be quantified). Legislation also very often lacks a dynamic regulatory regime which enables adjustments to changing environmental technologies (e.g. new pollution treatment processes) (Shane 1979) More often than not there is also no systematic approach for regular reviews of the appropriateness and efficiency of existing laws in the light of experiences gained (Biswas 1986).

These legislative shortcomings impede an efficient environmental management With increasing complexity of environmental problems and issues the legislation must also undergo a quick development and improvement in order not to lose its ability to tackle environmental pollution adequately. The existence of environmental laws, however is certainly not sufficient for proper environmental management. It is the process of implementation which is another critical issue and, indeed, it is even a more decisive factor for success or failure than legal measures.

\section{ENVIRONMENTAL ADMINISTRATION AND THE IMPLEMENT ATION OF ENVIRONMENTAL POLICIES}

For a successful implementation of environmental policy an efficient administration is of utmost importance which, on the basis of sound legislation, is in a position to vigorously enforce the environmental protection laws and regulations. It is more than obvious that laws - no matter how well formulated they are - which are not implemented in the intended way have at best a minimal impact on environmental quality.

Again the 1972 Stockholm conference can be seen as a turning point in environmental institution building in developing countries. In close connection with the development of environmental legislation after 1972 concerned administrations were installed [Lee (1982); Prinz (1984); Alam (1984); Thusen (1982)], as 
many laws directly stipulated the set-up of environmental institutions. The environmental administrations, however, vary substantially from country to country regarding the responsibility assigned to them. It ranges from policy-making at the one end to a co-ordination work or more advisory competence at the other (ESCAP 1984).

There is a long list of problems and deficiencies which severly hamper proper implementation of environmental legislation and policies. Most of them are common to almost all Asian developing countries, with varying intensities from one country to the other. Three areas of problems can be circumscribed: deficiencies within a single environmental body, the relationship between various environmental agencies and linkages between environmental administration and other administrative institutions.

Environmental administration is affected by problems, too, which are common to the general administration, such as the prevelance of 'personal-clientel relationship' instead of public interest orientation, overcentralization of the decision-making process and the like (Hartje 1984). The environmental institutions are particularly suffering from the general problem of lack of qualified personnel, as the required expertise normally cannot be obtained through traditional educational systems.

A severe administrative inadequacy is the division of environmental responsibilities amongst a multitude of agencies and a lack of co-ordinating mechanisms and of a harmonization of environmental regulatory activities. Moreover, the exploration and exploitation of natural resources and the responsibility for environmental management are generally divided; thus, the normal result is a lack of a continuing, comprehensive planning process which incorporates environmental quality and natural resource productivity considerations alike (Rees 1986).

Environmental administrations as a more recent phenomenon are in a comparatively unfavourable position when contending for financial recources against wellestablished administrations of other sectors. The result quite often is that they do not obtain the necessary allocation to perform their duties in a satisfactory manner. Especially the monitoring system is suffers heavily from inadequate provisions. Moreover, what is more important, they also possess inferior power to participate in decision-making processes and to enforce their own ideas and projects as compared with other government authorities. A further, specific problem, of many developing countries is the high degree of autonomy and power which semigovernmental and parastatal agencies (e.g. state oil companies, water and power authorities and the like which are amongst the large environmental polluters) enjoy so that their policies can be overcome only by authorities which are at the centre of political power (Hartje 1984). Environmental administrations commonly do not belong to this group so that their efforts are considerably thwarted.

Even more problematic is the fact that environmental administration is still considered as just an additional sector. It has never been regarded as a kind of new management approach which needs to pervade every existing sector of the economy and the administration. The objective "environmental protection" has not yet penetrated into other administrative agencies and the government. This lead to an almost complete neglect of environmental factors in administrations which are not directly concerned with environmental issues. It is, however, exactly this comprehensive approach combining environmental concerns with the administration of every development effort on which a successful environmental policy has to be built.

A very promising tool for such a comprehensive management approach is the concept of "Environmental Impact Assessment" (EIA). EIA means a formal planning procedure by which decision-makers obtain more comprehensive information on environmental implications of a development project. Its objective is to quantify possible environmental impacts of a project (or, where this is not possible, to give at least a qualitative assessment), to demonstrate the effects and costs of control measures and to present modifications for an abatement of environmental degradation.

In various Asian countries EIA has been applied in some way or other. East and Southeast Asian countries have been amongst the first developing countries which started operative EIA procedures [Hartje (1984); Goodland (1985)]. Pakistan established the system of "environmental impact assessment statements" in 1983 which however has not yet come into full operation.

Regarding EIA approaches we can again observe a large variety amongst the countries. They reach from a formal procedure to a performance on an ad hoc basis. Some countries prefer a system where the EIA is made by the investor himself and later reviewed by the concerned authority whereas in others the procedure is carried out by the authorities from the beginning.

As to the scope of the EIA we find considerable limitations. This is a factor which substantially hampers a successful environmental policy. In Indonesia only mining and industry are covered by the EIA, in Pakistan EIA is confined to industrial activities and in india it applies only to projects, where federal funds are involved [Goodland (1985); Hartje (1984); Hassan (1986)]. In addition, lack of trained personnel, lack of funds and vague terms of references are major hinderances for a successful application in at least these limited areas. Moreover, the results worked out by EIA-studies and proposals made for modifications of a project are often widely neglected by the concerned authorities and outweighed by other considerations. Thus, the whole EIA becomes, quite often, a futile exercise.

When one takes all these legislative, administrative and practical deficiencies described so far into consideration, it is no wonder that a lot of critical comments are made on the hitherto performance of environmental administration and the achievements of environmental policies in general in various Asian developing countries [Centre for Science and Environment (1982); Chee (1982); Donner (1987); Lee 
Table 3

Value Added in Manufacturing Industry of Selected Asian Countries 1984 (in Millions US \$ of 1980)

\begin{tabular}{lr}
\hline India & 30035 \\
China & 143822 \\
Pakistan & 5624 \\
Indonesia & 13165 \\
Philippines & 8644 \\
Thailand & 8325 \\
Malaysia & 6770 \\
South Korea & 26650 \\
\hline
\end{tabular}

Source: World Bank 1987

experienced a 500 percent expansion between 1960 and 1980, South Asia an in crement of 280 percent. In addition, a 300 percent increase is expected in the AsiaPasific region between 1985 and 2000 (Asian Development Bank 1987). Air pollution due to motor vehicles is exacerbated by the fact that all petrol is highly leaded.

\section{Water Pollution}

Heavily polluted rivers, lakes and coastal areas can be found in all Asian countries. A classification of the severity and extent of water pollution in fifteen Asian countries shows that one country has a severe pollution in widespread areas, seven countries have severe pollution in certain limited areas, and another four have moderate to severe pollution. Only three countries show a moderate pollution and in none of the countries the pollution is negligible (ESCAP 1984).

Regarding water pollution, the discharge of domestic waste accounts for the larger part of the contamination in most countries, whereas industrial activities are the second largest polluter. Thus, the trend of urbanization and concentration of population is the most important factor for future water contamination. But here, too, the prospects are quite discouraging, as the population of most metropolitan areas in Asia is likely to increase by about two-thirds or even more between 1985 and 2000. This means additional domestic waste in at least the same order of magnitude.

\section{Degradation of Forests}

Five million hectares of forests are lost in Asia every year and millions more are degraded by improper use. 63 percent of the originally forested area in South and 38 percent in Southeast Asia are now denuded. By the year 2000 Nepal is likely to be completely denuded. Rain forest degradation leads to severe ecological consequences. Loss of soil fertility, desertification, climatic changes, increased floods are some of the more important impacts. Forest depletion also leads to a significant loss of biological and species diversity. This has an effect on future agriculture, industry, science and on human welfare in general. So far, nobody has assessed the significance of these ecological losses regarding their long-term effect on economic earning power or opportunities for growth (Simonis 1984). Another economic consequence is that countries which used to export wood (e.g., Thailand, Malaysia, the Philippines) have to switch over to wood and timber imports. This means a substantial loss of foreign currency earnings.

Shifting cultivation and use for firewood are the main factors for deforestation. Another important factor is the industrial use and export of timber, which accounts for about 20 percent. These commercial activities, however, have a much larger impact, as they very often do pioneering work without which people would not be in a position to use a forest for shifting cultivation or other purposes.

\section{Use of Pesticides}

The application of pesticides in agriculture has rapidly increased in Asian countries during the last two decades. As there is a lack of expertise and of resources for control, many pesticides are indiscriminately used in third world countries which have been prohibited or severely restricted in industrial countries. The exporting industrial countries exercise little or no control over the export of banned or restricted pesticides. There is also a substantial lack of safety precautions in the use of pesticides. Users are either unaware of the need for such preventive measures or are unable to follow the safety precautions.

These factors almost inevitably lead to widespread accidental and occupational poisoning of human beings. In addition, long-term health effects of poisons result from their entering the human food chain. An improper use of hazardous pesticides also leads to serious threats for agricultural production, falling yields and rising costs due to rapidly increasing pesticide resistance and damages to beneficial species (Bull 1983). This again shows that environmental concern and economic considerations are not mutually exclusive, but on the contrary, tend to reinforce each other in many cases.

In developing countries, however, the opinion is still widely prevailing that pesticides are a panacea for agricultural growth. Therefore, they are vigorously promoted and their use is heavily subsidized. This general belief might also explain, why an adequate and effective pesticide control legislation is lacking in many developing countries. 


\section{CONCLUSIONS AND RECOMMENDATIONS}

The pollution of the environment and the degradation of natural resources have already reached alarming proportions in many Asian countries. Expected trends and forecasted developments of main pollution sources tend to suggest that the environment will further deteriorate if no serious steps for the protection of the environment are taken by the concerned governments.

Although almost all Asian countries have formulated an environmental policy in some way or other, introduced environmental legislation and set up environmental administrations, in actual practice specific objectives of environmental protection have not obtained sufficient importance in most countries. Environmental administration is not vested with actual political power to implement a policy properly and is not in a position to overcome other ministries and particular interests. All in all, there seems to be a lack of political will to include environmental considerations in the development strategy of a country.

The following general recommendations can contribute to overcoming some of the problems pointed out in this paper. The concept of "environment" should not be regarded as a separate issue to be added to other development priorities. It is rather an approach which has to be integrated in various other political fields (industrial policy, energy, agriculture, technology, etc.) and which gives more urgency to the sustainability of results and to the costs of deleterious side-effects in these areas of development. Environmental protection should also not be seen as a contradiction to development, as it is unfortunately often done in developing coun tries. The idea has to gain ground that on the basis of deteriorating environmental resources a satisfactory development process cannot take place. In the long run, development can only be achieved through sound environmental management. Thus, it must be the task of every rational environmental policy to foster such economic and technical processes which are environmentally benign and promote the development process at the same time and thus lead to an harmonization of "environment" and "development"

So far the environmental concept and environmental policy in developing countries were mainly ex-post oriented. Policy instruments were only taken, when the environment had already been damaged and resources had been exhausted. For successful environmental protection it is however necessary to switch over to preven tive measures and preserve the environment through an environmentally sound system of production and consumption. The experiences of the industrial countries suggest that in many circumstances an anticipatory approach is more successful and less costly than corrective techniques (Holdgate 1982). Environmental movements can play an important role in promoting the idea of environmental protection, in creating environmental awareness amongst the public and in environmental education. Environmental NGOs can also facilitate the implementation of environmental regulations and policies. Furthermore, they can strengthen the political power of environmental administrations vis- $a$-vis other administrative agencies, if environmental groups are not considered as opponents of governmental agencies, but as an important complement to and a possible supporter of their policy. This, unfortunately, is not yet the case in Asian countries, and the possible advantages emerging from ecological movements are not properly used.

\section{REFERENCES}

Alam, Sahabat Malaysia (1984). State of the Malaysian Environment 1984. Penang. Bank, Asian Development (1988). Annual Report 1987. Manila.

Bhargava, D. S. (1987). "Nature and Ganga". Environmental Conservation. Vol. 14, No. 4. pp. 307-318.

Biswas, A. K. (1986). "Environment and Law: A Perspective from Developing Countries”. Environmental Conservation. Vol. 13, No. 1.pp. 61-64.

Bull, D. (1983). "Pesticides and the Third World Poor". In W. Fernandes. (ed.), Forests, Environment and People. New Delhi.

Centre for Science and Environment (1982). “The State of India's Environment 1982". New Delhi.

Chee, G. T. (1982). "Public Participation and Responsibility". In T. Singh, T. P. Woon (eds.), The Malaysian Environment 10 Years after Stockholm. Proceedings of epsm-seminar; Petaling Jaya. pp. 77-82.

Donner, W. (1987). Land Use and Environment in Indonesia. London.

ESCAP (1984). State of the Environment in Asia and the Pacific. Vol. 1: Summary Bangkok.

Goodland, R. (1985). "Umweltpolitische Entwicklungen in Indonesien". Aus Politik und Zeitgeschichte. No. 33-34. pp. 5-14.

Pakistan, Government of (1987). "Environmental Profile of Pakistan". Islamabad Environment and Urban Affairs Division.

Hartje, V. (1982). Umwelt- und Ressourcenschutz in der Entwicklungshilfe: Beihilfe zum Uberleben? Frankfurt - New York.

Hartje, V. (1983). Industrialisierung und Umweltschutz in Entwicklungslandern; in: Deutscher Naturschutzring, Bundesverband fur Umweltschutz (eds.), Umweltgerechte Entwicklungspolitik. Bonn. pp. 96-122.

Hartje, V. (1984). "Environmental Impact Assessment for Development Projects". Zeitschrift fur Umweltpolitik. Vol. 7, No. 4. pp. 485-503.

Hassan, P. (1986). "Environmental Management in Pakistan". Viewpoint. Sept. 25 pp. $27-30$.

Holdgate, M. W., M. Kassas, and G. F. White (eds.) (1982). The World Environment 1972-1982. Dublin.

Lee, M. (1982). Wirtschaftswachstum und Umweltentwicklung in Sudkorea; in: 
Landschaft + Stadt. Vol. 14, No. 4. pp. 153-158.

Prinz, B., and E. Koch (1984). Umweltpolitik und Technologische Entwicklung in der Volksrepublik China; LIS-Bericht Nr. 16, Essen,

Rees, C. (1986). "Environmental Policies and Economic Development". Asian Development Review. Vol. 4, No. 1. pp. 63-77.

Shane, J. (1979). "Environmental Law in the Developing Nations of Southeast Asia". In C. MacAndrews and C. L. Sien (eds.), Developing Economies and the Environment. The Southeast Asian Experience. Singapore.

Simonis, U. E. (1984). "Developing Countries in the Environmental Crisis". Intereconomics. September/October. pp. 239-243.

Walter, I., J. Ugelo (1979). "Environmental Policies in Developing Countries". Ambio. Vol. 8, No. 2. pp. 102-109.

Zhao, D., Z. Bozen (1986). "Air Pollution and Acid Rain in China". Ambio. Vol. 15, No. 1. pp. 2-5.

\section{Comments on \\ "Environmental Crises and Environmental Policies in Asian Countries"}

Being the first paper which addresses the issue of environmental policies in Pakistan, the paper is an interesting endeavour. According to the author, the external cost of economic development in the form of environmental degradation has reached alarming levels in most Asian Countries which justifies direct attention of policymakers and researchers alike.

To call attention to the environmental crisis and thus environmental management required is, in my opinion, also the main purpose of the paper. The discussion of the paper will, therefore, concentrate on whether the author has been successful in generating this interest, at least from the researchers. For that matter, first a brief on the paper will be given followed by some observations.

An historical overview of the enacted environmental legislation in Asian countries since 1972 leads to the conclusion that these legislation are only vaguely phrased and do not reflect the current values presently prevailing in Asian societies. Besides, the institutions established to execute the policies are hampered in their effective functioning due to the lack of trained personnel, co-ordination, finance and political priority.

Based on the failures of the prevailing environmental management concept in Asian countries, the author advocates a more comprehensive approach which should be tied to the concept of development. As a corollary, the objectives and the aims of the concept should be clearly defined in the economic and cultural context of developing countries. This means, the environmental policies should not only be formulated for the pollution emanating from industrial projects but should also encompass polluters specific to the developing countries, like domestic waste discharge, firewood use for energy consumption, pesticide use in agriculture, number of vehicles in metropolitan areas, etc. Besides, public awareness for environmental pollution in its various identities should be aroused for which environmental movements can be instrumental. These movements should join hands with the environmental administration and stress conscious behaviour.

Based on the review of the content of the paper, the paper is restricted to the general observation that environmental policies should be formulated within a 
development concept. Nothing is explicitly mentioned on the operationalization of the approach in terms of data collecton and fields of research. Those factors are essential to arouse the interest of researchers. Consequently, additional efforts are required to be addressed to these issues.

Ivo C. Havinga

Institute of Social Studies,

The Hague,

The Netherlands 